\title{
The Development of Porcine Parthenogenetic Diploid Oocytes with Homogeneous Genomic Components In Vitro
}

\author{
Nguyen Van THUAN" ${ }^{1)}$, Hiroshi HARAYAMA ${ }^{1)}$ and Masashi MIYAKE ${ }^{1)}$ \\ ${ }^{1)}$ Department of Life Science, Graduate School of Science and Technology, Kobe University \\ 1-1 Rokkodai-cho Nada-ku, Kobe City, Hyogo 657-8501, Japan
}

\begin{abstract}
The aim of this study was to determine the influence of the homogeneity of genomic components and ploidy on the in vitro development of porcine parthenogenetic oocytes to the blastocyst stage. In vitro matured oocytes were subjected to a single pulse of electro-stimulation (El-St; $100 \mu \mathrm{sec}, 1,500 \mathrm{~V} / \mathrm{cm}$ ) for activation. First, the activated oocytes were cultured for $6,16,18,20$ and 22 $\mathrm{h}$ after El-St, and examined for the timing of the first cleavage of parthenogenetic haploids. Next, the effects of the timing and duration of cytochalasin B (CB) treatment on inhibition of the first cleavage of haploids were examined in order to produce homogenous parthenogenetic diploids. Then the developmental ability to the blastocyst stage was compared among activated oocytes with genomic components of haploid (without CB treatment), homogeneous diploid (nn-diploid, CB treatment for 6 $\mathrm{h}$ from $20 \mathrm{~h}$ after El-St), and heterogeneous diploid (nn'-diploid, CB treatment for $4 \mathrm{~h}$ immediately after El-St). Most haploids were at the prophase to telophase of the first cleavage between 16 and $22 \mathrm{~h}$ after El-St. When the haploids were treated with $5.0 \mu \mathrm{g} / \mathrm{ml} \mathrm{CB}$ for $6 \mathrm{~h}$ from $20 \mathrm{~h}$ after El-St, their first cleavage was efficiently suppressed, and most of them $(84 \%)$ became diploids. The frequency of parthenogenetic development to the blastocyst stage was significantly lower in haploids ( $5 \%$ ) than in nn-diploids $(48 \%, \mathrm{P}<0.01)$ or $\mathrm{nn}^{\prime}$-diploids $(57 \%, \mathrm{P}<0.01)$. These results shows that ploidy of activated oocytes, but not the homology of genomic components, affects the development of porcine parthenogenetic oocytes to the blastocyst stage.
\end{abstract}

Key words: Porcine parthenogenesis, Ploidy, In vitro development

(J. Reprod. Dev. 48: 157-166, 2002)

$\mathbf{T}$ he genotype of the parthenogenetic embryo varies depending on the experimental conditions and on the postovulatory age of the oocyte. Matured oocytes have two genomic sets of chromosomes, one which is delivered to the egg and the other which is shared by the second polar body. Each chromosome consists of a mixture of paternal and maternal genomic components by the process of crossing-over during the meiotic prophase I. Thus the two genomic sets are not exactly identical. Therefore, the possible genotypes arising from parthenogenetic activation are

Accepted for publication: November 29, 2001

Correspondence: M. Miyake uniform haploids with the extrusion of the second polar body (n), mosaic haploids through an immediately equal cell-division but not extrusion of the second polar body $\left(n+n^{\prime}\right)$, and heterogeneous diploids without the extrusion of the second polar body ( $\left.\mathrm{nn}^{\prime}\right)$ according to the theoretical classification by Kaufman [1]. It has been reported, however, that porcine oocytes matured less than $48 \mathrm{~h}$ followed by artificial activation actually yielded activated eggs of uniform haploid type (about 90\%) or of heterogeneous diploid type with two haploid $\left(\mathrm{n}+\mathrm{n}^{\prime}\right)$ nuclei or a single diploid $\left(\mathrm{nn}^{\prime}\right)$ nucleus (a few percentage each), but no mosaic-haploid activated oocytes $[2,3]$. 
Many studies have reported that in vitro matured porcine oocytes were activated in response to a treatment with $\mathrm{Ca}^{2+}$ ionophores [4,5], electrical stimulation [2, 6-8], protein kinase inhibitors [9], cycloheximide [10], and ethanol [11]. A high percentage of the activated oocytes cleaved to the 2cell stage $24 \mathrm{~h}$ after El-St irrespective of treatment with cytochalasin B (CB treatment), whereas only limited percentages of the activated oocytes developed to the blastocyst stage in haploid oocytes without CB treatment. On the other hand, presumptive diploid oocytes produced by $\mathrm{CB}$ treatment just after electro-stimulation (El-St) showed relatively high developmental ability to the blastocyst stage $[7,11]$. These results suggest that the developmental ability of porcine parthenogenetic oocytes to the blastocyst stage might be dependent on the extrusion of second polar bodies, namely diploids or haploids. In this regard, it has been reported that the developmental potential of parthenogenetic mouse oocytes with two pronuclei is much better than that of the oocytes with one pronucleus in the mouse $[1,12]$.

Parthenogenetic diploids are usually produced by inhibiting the extrusion of the second polar body during the resumption of the second meiosis. As described above, the porcine parthenogenetic haploid, which has only one set of chromosomes, shows lower developmental ability to the blastocyst stage than parthenogenetic diploids [6, 11, 13]. It had previously been believed, therefore, that failure of full-term development in parthenogenesis in mammals was partially due to a lack of spare alleles of specific recessive genes, before it was shown in the mouse that different gene imprinting between male and female gametes results in developmental cessation of mammalian parthenogenesis at the early stage of postimplantation [14-16]. There is no evidence, however, that uniformity in all alleles has any effect on the preimplantational development of parthenogenetic diploids. In this study, we produced diploids with homogeneous genomic sets (nn) by CB treatment of porcine haploids (n) during the first cleavage. We investigated the effects of the homogeneity of genomic components in parthenogenetic diploids on the in vitro development to the blastocyst stage in the pig.

\section{Materials and Methods}

Oocyte collection, in vitro maturation and electrostimulation

Porcine ovaries, which were collected at local abattoirs, were kept at 20-30 C and transported to our laboratory within $2 \mathrm{~h}$. Ovaries were washed once with $0.2 \%(\mathrm{w} / \mathrm{v})$ cetyltrimethylammonium bromide (Wako Pure Chemical Industries, Ltd., Osaka, Japan) and twice with $\mathrm{Ca}^{2+}$ - and $\mathrm{Mg}^{2+}$-free Dulbecco's phosphate-buffered saline (PBS) containing $0.1 \%(\mathrm{w} / \mathrm{v})$ polyvinyl alcohol (PBSPVA; Sigma Chemical Co., St. Louis, MO). Follicles 4 to $6 \mathrm{~mm}$ in diameter were dissected out in PBSPVA. Only those that had a round form and clear follicular fluid without detachment of granulosa cells and an oocyte were ruptured. Oocytes with a cumulus oophorus and a portion of parietal granulosa cells were removed from follicles in 25 mM 2-[4-(2-hydroxyethyl)-1- piperazinyl] ethanesulfonic acid (Dojindo Lab. Co., Ltd., Kumamoto, Japan) buffered TCM-199 medium (Earl's salt; Nissui Pharmaceutical Co., Ltd., Tokyo, Japan) containing $0.1 \%(\mathrm{w} / \mathrm{v})$ polyvinyl alcohol (HEPES-TCM). The oocyte-cumulus-granulosa cell complexes (OCGCs) were then washed with fresh HEPES-TCM, followed by maturation medium. The maturation medium was based on bicarbonatebuffered TCM-199 containing 10\% (v/v) heattreated fetal calf serum (Biocell Inc., Carson, CA), $0.1 \mathrm{mg} / \mathrm{ml}$ sodium pyruvate (Nacalai Tesque Inc., Kyoto, Japan), $0.08 \mathrm{mg} / \mathrm{ml}$ kanamycin sulphate (Sigma), $2.2 \mathrm{mg} / \mathrm{ml}$ sodium bicarbonate (mTCM; Nacalai Tesque Inc.), and $0.1 \mathrm{IU} / \mathrm{ml}$ human menopausal gonadotropin (Pergonal; Serono, Rome, Italy). Before maturation culture, OCGCs were morphologically assessed under a stereomicroscope, and only oocytes that had a homogeneous ooplasm with a compact and clear cumulus oophorus were selected. Each group of fewer than 50 oocytes was transferred to $2.0 \mathrm{ml}$ of the maturation medium in a polystyrene dish $(35 \times$ $10 \mathrm{~mm}$; Beckton Dickinson Labware, NJ). Two theca shells that were collected from healthy follicles of 4-6 mm in diameter were added to the dish after removal of follicular fluid and granulosa cells using two pairs of fine forceps. The mixtures of OCGCs and follicle shells were cultured in a $\mathrm{CO}_{2}$ incubator at $38.5 \mathrm{C}$ under humidified air containing $5 \% \mathrm{CO}_{2}$ with gentle agitation for $48 \mathrm{~h}$. 
After maturation culture, $200 \mu \mathrm{l}$ of $0.1 \%(\mathrm{w} / \mathrm{v})$ hyaluronidase (Type I-S; Sigma) in PBS-PVA was added to the maturation medium. Several minutes later, oocytes were transferred to $100 \mu \mathrm{l}$ drops of mTCM which had been previously covered with paraffin oil (analytical grade for analysis of amino acids; Nacalai) in a polystyrene culture dish $(60 \times 15$ $\mathrm{mm}$; Beckton Dickinson Labware, NJ) and were freed from almost all cumulus cells by gentle pipetting. Denuded oocytes were transferred to new drops of $\mathrm{mTCM}$ to rinse off the hyaluronidase solution. The extrusion of the first polar body was inspected under an inverted microscope to assess oocyte maturation. The oocytes with the first polar body were washed three times in a field solution that was composed of $0.3 \mathrm{mM}$ mannitol, $0.1 \mathrm{mM}$ $\mathrm{MgSO}_{4}$ and $0.05 \mathrm{mM} \mathrm{CaCl}_{2}$ [17], and was supplemented with $0.01 \%(\mathrm{w} / \mathrm{v})$ polyvinyl alcohol (PVA). Each group of less than 20 oocytes was transferred to $100 \mu$ lof the field solution between two parallel stainless electrodes in a chamber (FTC03; Shimadzu Co., Ltd., Kyoto, Japan). A single direct-current pulse of $1,500 \mathrm{~V} / \mathrm{cm}$ for $100 \mu \mathrm{sec}$ was supplied from an electro cell manipulator (ECM 2000; BTX Inc., San Diego, CA).

\section{Culture media for development}

The culture medium was Whitten's medium (WM) [18] supplemented with $4.0 \mathrm{mg} / \mathrm{ml}$ bovine serum albumin (BSA; Intergen, Purchase, NY) and $0.5 \mathrm{mg} / \mathrm{ml}$ hyaluronic acid (from rooster comb; Seikagaku Co., Tokyo, Japan) (mWM) [6, 19]. The osmolarity of the culture medium was kept at 309 mOsmol (mWM309) for the first 48 or $72 \mathrm{~h}$ by addition of $26.2 \mathrm{mM} \mathrm{NaCl}$ to $\mathrm{mWM}$ and then 256 mOsmol (mWM256) until $192 \mathrm{~h}$ after El-St [20].

Experiment 1: Determination of the period of the first cleavage in parthenogenetic haploids

Activated oocytes were cultured in $30 \mu \mathrm{l}$ of mWM309. They were fixed with acetic ethanol (acetic acid : ethanol $=1: 3$ ) at 6, 16, 18, 20, or $22 \mathrm{~h}$ after El-St, and then stained with $1 \%$ orcein. The morphology of the nucleus during the first cleavage was examined under a differential interference microscope (Optiphoto; Nikon, Tokyo, Japan).

Experiment 2: Cytochalasin B (CB) treatment for duplication of the haploid genome at the first cleavage

Activated oocytes were cultured in mWM309 for $16,18,20$ or $22 \mathrm{~h}$ after El-St, and then were transferred to mWM309 including $5.0 \mu \mathrm{g} / \mathrm{ml} \mathrm{CB}$ for 4 or $6 \mathrm{~h}$ to determine the optimal timing and duration of the $\mathrm{CB}$ treatment after El-St. After CB treatment, oocytes were washed four times with mWM309, and were further cultured in mWM309 until $48 \mathrm{~h}$ after El-St. The numbers of polar bodies and blastomeres in oocytes were examined for determination of their ploidy before subsequent culture.

\section{Experiment 3: Estimation and examination of the} ploidy of activated oocytes after treatment with $C B$ for $6 \mathrm{~h}$ from $20 \mathrm{~h}$ after El-St

From the results of Experiment 2, activated oocytes were treated with $5.0 \mu \mathrm{g} / \mathrm{ml} \mathrm{CB}$ for $6 \mathrm{~h}$ from $20 \mathrm{~h}$ after El-St. They were then further cultured in $\mathrm{mWM} 309$, and oocytes were fixed at 2-h intervals until $22 \mathrm{~h}$ after CB treatment (28 to $48 \mathrm{~h}$ after El-St). The oocytes were washed three times with PBS-PVA and then treated with $0.01 \%$ pronase (actinase E; Sigma) in PBS-PVA for 3 to $5 \mathrm{~min}$ to induce expansion of the zona pellucida. The oocytes were then transferred into a small drop of heat-treated FCS to inhibit the activity of pronase. Subsequently, they were placed in a hypotonic solution, which was made by dilution of PBS-PVA with the same volume of distilled water (hypoPBS), for 2 to $3 \mathrm{~min}$ to swell the ooplasm. The oocytes were fixed quickly by addition of acetic ethanol to a drop of hypo-PBS, and were wholemounted with a small volume of the fixative on a slide glass. The number of chromosomes of each spread was determined under a differential interference microscope after staining with $1 \%$ aceto-orcein.

\section{Experiment 4: In vitro development of activated diploids with homogeneous genomic sets to the blastocyst stage}

To compare the developmental ability to the blastocyst stage, haploid oocytes (haploids), heterogeneous diploids (nn'-diploids) and homogeneous diploids (nn-diploids) were cultured as follows. Electro-stimulated oocytes were divided into three portions at each trial. One portion of the oocytes were cultured in mWM309 containing $5.0 \mu \mathrm{g} / \mathrm{ml}$ of CB for $4 \mathrm{~h}$ to produce $\mathrm{nn}^{\prime}-$ diploids by inhibition of the extrusion of the second polar body $[7,8]$. After CB treatment, the oocytes were washed five times with $\mathrm{mWM} 309$, cultured up to $48 \mathrm{~h}$, and then cultured in mWM256 until 192 
h after El-St.

The remaining two portions of activated oocytes were immediately transferred to spots of mWM309, and were examined 6 to $8 \mathrm{~h}$ after El-St on an inverted microscope to confirm the extrusion of the second polar body. Only oocytes with the second polar body were subsequently cultured in mWM309. One portion of the oocytes was cultured up to $48 \mathrm{~h}$ in mWM309, and then cultured from $48 \mathrm{~h}$ to $192 \mathrm{~h}$ in mWM256 after El-St to determine the developmental ability of parthenogenetic haploids. Another portion of the oocytes with a second polar body was cultured in mWM309 up to $20 \mathrm{~h}$ after El$\mathrm{St}$, and then for $6 \mathrm{~h}$ in mWM309 containing $5.0 \mu \mathrm{g} /$ $\mathrm{ml}$ of $\mathrm{CB}$ to produce parthenogenetic nn-diploids. Oocytes were washed five times with mWM309. The presumptive nn-diploids were further cultured in mWM309 up to $72 \mathrm{~h}$, and then in mWM256 from $72 \mathrm{~h}$ to $192 \mathrm{~h}$ after El-St. At the end of culture, all of the blastocysts of nn-diploids and $\mathrm{nn}^{\prime}$-diploids were stained with $2 \mu \mathrm{g} / \mathrm{ml}$ Hoechst 33342 (Polysciences Inc., Warrington, PA) and then the number of cells in each blastocyst was counted under an epifluorescence microscope (Nikon).

\section{Statistical analysis}

The resulting data were subjected to arcsine transformation in each replication. The transformed values were analyzed using one-way ANOVA. When the ANOVA revealed a significant effect, the treatments were compared by Student's $t$-test. The numbers of nuclei in blastocysts were also analyzed by Student's t-test following one-way ANOVA. A probability of less than 0.05 was considered to indicate statistical significance.

\section{Results}

Experiment 1: Determination of the period of the first cleavage in parthenogenetic haploids

The nuclear conditions of parthenogenetic haploids from 6 to $22 \mathrm{~h}$ after El-St are summarized in Table 1. Almost all haploids (96\%) accomplished formation of a single nucleus $6 \mathrm{~h}$ after El-St. The most dominant nuclear stage of haploids was prometaphase, metaphase, anaphase and telophase at 16, 18, 20 and $22 \mathrm{~h}$ after El-St, respectively. Haploids at the 2-cell stage were first observed $22 \mathrm{~h}$ after El-St.

Experiment 2: Optimal timing of CB treatment for duplication of the haploid genome at the first cleavage

After treatment with $5.0 \mu \mathrm{g} / \mathrm{ml} \mathrm{CB}$ for $4 \mathrm{~h}$ from 16 to $22 \mathrm{~h}$, activated oocytes were further cultured up to $48 \mathrm{~h}$ after El-St, and their number of blastomeres after 24 and $48 \mathrm{~h}$ of culture are summarized in Table 2. Inhibition of the first cleavage of activated oocytes by the treatment was estimated by the reduction of the number of blastomeres. More than $70 \%$ of the oocytes that were treated with CB from 16, 18 and $22 \mathrm{~h}$ after ElSt were at the 2- and 4-cell stages at 24 and $48 \mathrm{~h}$, respectively. In the oocytes that were treated from $20 \mathrm{~h}$ after El-St, the frequencies of 1-cell and 2-cell oocytes were significantly lower than those after the other treatments at 24 and $48 \mathrm{~h}$ after El-St $(\mathrm{P}<0.01)$. The activated oocytes at the 1-cell and 2cell stages at 24 and $48 \mathrm{~h}$, respectively, were considered oocytes whose first cell cleavage was inhibited. Thus, the first cleavage was efficiently prevented in the oocytes only after treatment with CB from $20 \mathrm{~h}(\mathrm{P}<0.01)$. However, because the

Table 1. Nuclear conditions of parthenogenetic haploids from 6 to $22 \mathrm{~h}$ after electro-stimulation in the pig

\begin{tabular}{|c|c|c|c|c|c|c|c|c|}
\hline \multirow{2}{*}{$\begin{array}{l}\mathrm{h} \text { after } \\
\text { El-St }\end{array}$} & \multicolumn{2}{|c|}{ No. $(\%)$ of oocytes } & \multicolumn{6}{|c|}{ Number $(\%)$ of oocytes at the stage of } \\
\hline & Stimulated & Activated & Nucleus & Promet & Meta & Ana & Telo & 2-cell \\
\hline 6 & 110 & $106(96)^{*}$ & $96(100)$ & - & - & - & - & - \\
\hline 16 & 108 & 100(93) & $0(0)$ & 97(97) & $3(3)$ & $0 \quad(0)$ & $0(0)$ & $0(0)$ \\
\hline 18 & 189 & 177(94) & $0(0)$ & $14(8)$ & $150(85)$ & $12(7)$ & $0(0)$ & $0(0)$ \\
\hline 20 & 179 & 174(97) & $0(0)$ & $0(0)$ & $7(4)$ & $143(82)$ & $24(14)$ & $0(0)$ \\
\hline 22 & 106 & 103(97) & $0(0)$ & $0(0)$ & $0(0)$ & $5(5)$ & $93(90)$ & $5(5)$ \\
\hline (Non El-St) & 128 & $0(0)$ & - & - & - & - & - & \\
\hline
\end{tabular}

* : Only activated oocytes with two polar bodies.

Promet; prometaphase, Meta; metaphase, Ana; anaphase, Telo; telophase.

Non El-St: Matured oocytes were fixed at $6 \mathrm{~h}$ after culture in $\mathrm{mWN}_{309}$. 
Table 2. Effects of starting-time of 4-h treatment with cytochalasin B (CB) after electro-stimulation on the prevention of the first cleavage of porcine parthnogenetic hapoids

\begin{tabular}{|c|c|c|c|c|c|c|c|}
\hline \multirow{3}{*}{$\begin{array}{l}\text { Timing* } \\
\text { of CB } \\
\text { Treat. }\end{array}$} & \multirow{3}{*}{$\begin{array}{l}\text { No. of } \\
\text { oocytes } \\
\text { examined }\end{array}$} & \multicolumn{6}{|c|}{ Percentages of activated oocytes at the stage of } \\
\hline & & \multicolumn{3}{|c|}{$24 \mathrm{~h}$ after El-St } & \multicolumn{3}{|c|}{$48 \mathrm{~h}$ after El-St } \\
\hline & & 1-cell & 2-cell & Degen. & 2-cell & $\begin{array}{l}\text { 3- to } \\
\text { 4-cell }\end{array}$ & Degen. \\
\hline $16 \mathrm{~h}$ & 186 & $6.4^{\mathrm{a}}$ & $90.9^{\mathrm{a}}$ & 2.7 & $7.5^{\mathrm{a}}$ & $76.3^{\mathrm{a}}$ & 16.1 \\
\hline 18 & 178 & $6.2^{\mathrm{a}}$ & $86.5^{\mathrm{a}}$ & 7.3 & $12.9^{\mathrm{a}}$ & $73.6^{\mathrm{a}}$ & 13.5 \\
\hline 20 & 210 & $74.8^{\mathrm{b}}$ & $15.7^{\mathrm{b}}$ & 9.5 & $65.2^{\mathrm{b}}$ & $19.5^{\mathrm{b}}$ & 15.3 \\
\hline 22 & 192 & $14.1^{\mathrm{a}}$ & $76.6^{\mathrm{a}}$ & 9.3 & $12.5^{\mathrm{a}}$ & $72.4^{\mathrm{a}}$ & 15.1 \\
\hline
\end{tabular}

* : Matured oocytes were treated with $5.0 \mathrm{mg} / \mathrm{ml}$ cytochalasin $\mathrm{B}(\mathrm{CB})$ for $4 \mathrm{~h}$ from the indicated hours after electro-stimulation. El-St, Electro-stimulation; Degen., Degeneration.

Figures with different superscripts in the same column are significantly different $(\mathrm{a}, \mathrm{b} P<0.01)$.

Table 3. Effects of duration of the cytochalasin B (CB) treatment on the prevention of the first cleavage of porcine parthenogenetic haploids

\begin{tabular}{|c|c|c|c|c|c|c|c|}
\hline \multirow{3}{*}{$\begin{array}{l}\text { Duration } \\
\text { of } \mathrm{CB} \\
\text { treatment }\end{array}$} & \multirow{3}{*}{$\begin{array}{c}\text { No. of } \\
\text { oocytes } \\
\text { examined }\end{array}$} & \multicolumn{6}{|c|}{ Percentages of activated oocytes at the stage of } \\
\hline & & \multicolumn{3}{|c|}{$24 \mathrm{~h}$ after El-St } & \multicolumn{3}{|c|}{$48 \mathrm{~h}$ after El-St } \\
\hline & & 1-cell & 2-cell & Degen. & 2-cell & $\begin{array}{l}3 \text { - to } \\
\text { 4-cell }\end{array}$ & Degen. \\
\hline $4.0 \mathrm{~h}$ & 110 & $67.3^{\mathrm{a}}$ & $26.4^{\mathrm{a}}$ & 6.3 & $62.7^{\mathrm{a}}$ & $28.2^{\mathrm{a}}$ & 9.1 \\
\hline 6.0 & 126 & $88.9^{\mathrm{b}}$ & $7.1^{\mathrm{b}}$ & 4.0 & $84.9^{\mathrm{b}}$ & $8.7^{\mathrm{b}}$ & 6.4 \\
\hline
\end{tabular}

El-St, Electro-stimulation; Degen., Degeneration.

Figures with different superscripts in the same column are significantly different $(\mathrm{a}, \mathrm{b} P<0.05)$.

frequency of the inhibition of the first cleavage $(65.2 \%)$ was not sufficiently high to examine their developmental ability, the duration of the CB treatment was prolonged from 4 to $6 \mathrm{~h}$ (Table 3 ). $\mathrm{CB}$ treatment for $6 \mathrm{~h}$ resulted in an increase of the frequency of the inhibition of the first cleavage at 24 h $(67 \%$ to $89 \%, \mathrm{P}<0.05)$ and $48 \mathrm{~h}(63 \%$ to $85 \%$, $\mathrm{P}<0.05)$.

Experiment 3: Estimation and examination of the ploidy of activated oocytes after treatment with cytochalasin B for $6 \mathrm{~h}$ from $20 \mathrm{~h}$ after El-St

A total of 251 activated oocytes with two polar bodies were subjected to CB treatment, and 233 and 18 oocytes were at the 1-cell and 2-cell stages at the end of CB treatment, respectively. At this point, only oocytes at the 1-cell stage were subjected to further culture for estimation and determination of their ploidy. The number of chromosomes could be counted in only 38 oocytes, resulting in a frequency of diploids of $84 \%$ (Table 4 and Fig. 1). Although the mean frequency of the estimated diploids was $72 \%$ due to the large number of undetermined oocytes during the mitosis, the frequency of estimated diploids was constant and high (mean, $82.7 \%$; range, $80-90 \%$ ) among the oocytes examined at 26 to $34 \mathrm{~h}$ and 44 to $48 \mathrm{~h}$ after El-St. It was also clearly shown that the prometaphase of the first cleavage of homogeneous diploids after $C B$ treatment started at $32 \mathrm{~h}$, and was completed approximately $42 \mathrm{~h}$ after El-St.

\section{Experiment 4: In vitro development of activated diploids with homogeneous genomic sets to the blastocyst stage}

The frequencies of development to the 2-cell and 4 -cell stages at 24 and $48 \mathrm{~h}$ after El-St were significantly lower in nn-diploids $(10 \%$ and $13 \%$, respectively) than in haploids $(96 \%$ and $83 \%$, respectively) or $\mathrm{nn}^{\prime}$-diploids [ $(92 \%$ and $86 \%$; $\mathrm{P}<0.05$ )(Fig. 2)]. The developmental delay of nndiploids was recovered, and the distribution of the 
Table 4. The nuclear conditions and the ploidy of activated oocytes 26 to $48 \mathrm{~h}$ after treatment with $5.0 \mu \mathrm{g} / \mathrm{ml}$ cytochalasin $\mathrm{B}$ for $6 \mathrm{~h}$ from $20 \mathrm{~h}$ after electro-stimulation

\begin{tabular}{|c|c|c|c|c|c|c|c|c|c|c|}
\hline \multirow{3}{*}{$\begin{array}{l}\text { Hours } \\
\text { after } \\
\text { El- St. }\end{array}$} & \multirow{3}{*}{$\begin{array}{c}\text { No. of } \\
\text { oocytes } \\
\text { examined }\end{array}$} & \multicolumn{9}{|c|}{ Number (\%) of oocytes with nuclear conditions of } \\
\hline & & \multicolumn{2}{|c|}{ Interphase } & \multicolumn{2}{|c|}{ Cleaving } & \multicolumn{2}{|c|}{ Interphase } & \multirow{2}{*}{$\begin{array}{c}\text { Abnormal } \\
\text { or not } \\
\text { determined }\end{array}$} & \multicolumn{2}{|c|}{ Estimated ploidy } \\
\hline & & $2 \mathrm{~N}$ & $1 \mathrm{~N}$ & Diploid & Haploid & 2- cell & $\begin{array}{l}3 \text { - to } \\
4 \text { - cell }\end{array}$ & & diploid & haploid \\
\hline 26 & 20 & $17(85)$ & $2(10)$ & $0(0)$ & $0(0)$ & $0(0)$ & $0(0)$ & $1(5)$ & $17(85)$ & $2(10)$ \\
\hline 28 & 20 & $16(80)$ & 2(10) & $0(0)$ & $0(0)$ & $0(0)$ & $0(0)$ & $2(10)$ & $16(80)$ & $2(10)$ \\
\hline 30 & 20 & $18(90)$ & $1(5)$ & $0(0)$ & $0(0)$ & $0(0)$ & $0(0)$ & $1(5)$ & $18(90)$ & $1(5)$ \\
\hline 32 & 20 & $13(65)$ & $0(0)$ & $3(15)$ & $1(5)$ & $0(0)$ & $0(0)$ & $3(15)$ & $16(80)$ & $1(5)$ \\
\hline 34 & 25 & $4(16)$ & $0(0)$ & $16(64)$ & $2(8)$ & $0(0)$ & $0(0)$ & $3(12)$ & $20(80)$ & $2(8)$ \\
\hline 36 & 27 & $1(4)$ & $0(0)$ & $8(32)$ & $3(12)$ & $1(4)$ & $0(0)$ & $14(56)^{*}$ & $10(37)$ & $3(12)$ \\
\hline 38 & 25 & $0(0)$ & $0(0)$ & $2(8)$ & $0(0)$ & $13(52)$ & $2(8)$ & $8(32)^{*}$ & $15(60)$ & $2(8)$ \\
\hline 40 & 23 & $0(0)$ & $0(0)$ & $3(13)$ & $0(0)$ & $12(52)$ & $2(9)$ & $6(26)^{*}$ & $15(65)$ & $2(9)$ \\
\hline 42 & 25 & $0(0)$ & $0(0)$ & $0(0)$ & $0(0)$ & $18(75)$ & $3(13)$ & $4(17)^{*}$ & $18(75)$ & $3(13)$ \\
\hline $44-48$ & 28 & $0(0)$ & $0(0)$ & $0(0)$ & $0(0)$ & $23(82)$ & $4(14)$ & $1(4)$ & $23(82)$ & $4(14)$ \\
\hline Total & 233 & - & - & $32(84)^{* *}$ & $6(16)^{* *}$ & - & - & 43 (19) & 168(72) & $22(9)$ \\
\hline
\end{tabular}

*: Abnormal or not determined oocytes included $12,7,5$ and 3 eggs at the late anaphase to telophase at $36,38,40$ and $42 \mathrm{~h}$ after electro- stimulation, respectively. The number of chromosomes could not be counted at these stages. ${ }^{* *}$ : Number $(\%)$ of diploid or haploid oocytes for which the number of chromosomes could be counted.

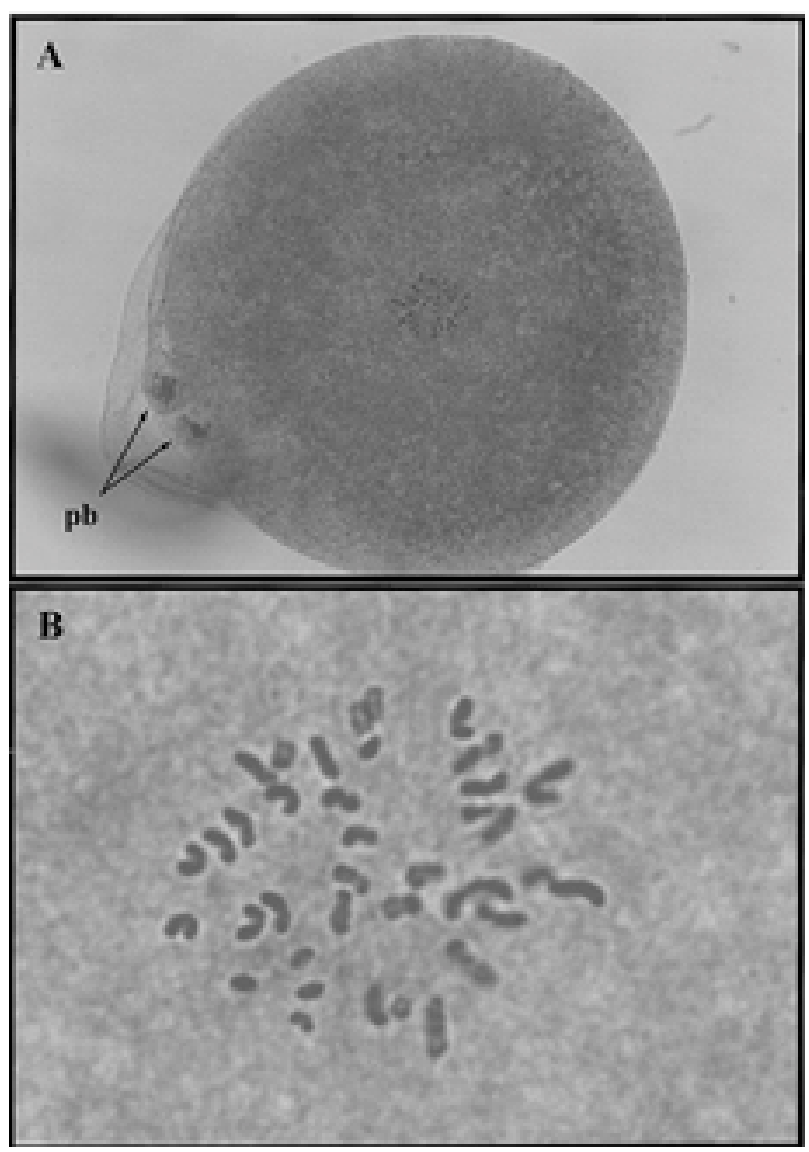

Fig. 1. Diploid chromosomes of a porcine parthenogenetic oocyte. A. A homogeneous porcine parthenogenetic diploid oocytes with the first and second polar bodies. B. High magnification of A. Thirty-eight chromosomes can be recognized. developmental stages was very similar among the three kinds of parthenogenotes at 72 and $96 \mathrm{~h}$ after El-St. The frequency of the abnormal oocytes was significantly increased, and the rate of morulae in haploids $(48 \%)$ was significantly lower than that in either nn'- $(67 \%)$ or nn-diploids $(62 \%)$ at $120 \mathrm{~h}$ after El-St $(\mathrm{P}<0.05)$. Haploids suddenly stopped developing at the morula stage, and only $5 \%$ of stimulated oocytes showed formation of the blastocoel at $168 \mathrm{~h}$ after El-St. No haploid blastocysts expanded, whereas most haploids (95\%) showed developmental abnormalities later than $168 \mathrm{~h}$. Finally, the frequencies of development to the blastocyst and expanded blastocyst stages were significantly higher in nn'- (31 and 26\%) and nn-diploids (27\% and $22 \%)$ than in haploids (5\% and $0 \%$, respectively; $\mathrm{P}<0.05)$. Both $\mathrm{nn}^{\prime}-$ and $\mathrm{nn}-$ diploids showed very similar developmental patterns from $72 \mathrm{~h}$ to $192 \mathrm{~h}$ after El-St in spite of the obvious delay of the development in nn-diploids before $48 \mathrm{~h}$. There was no significant difference in the mean number of nuclei between the nn-diploid blastocysts $(43.6 \pm 4.5, \mathrm{n}=60)$ and nn'-diploid blastocysts $(41.3 \pm 4.7, \mathrm{n}=57)$.

\section{Discussion}

Mature porcine oocytes are known to be easily activated by a single electro-stimulation; their frequency of activation has been reported as more 

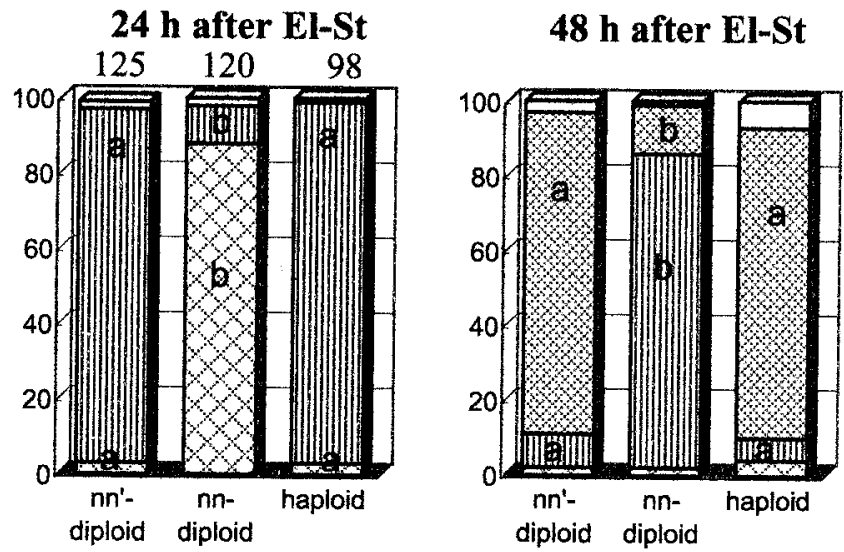

72 h after El-St

$96 \mathrm{~h}$ after El-St

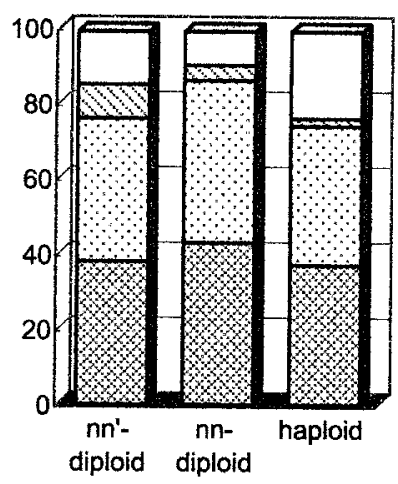

120 h after El-St
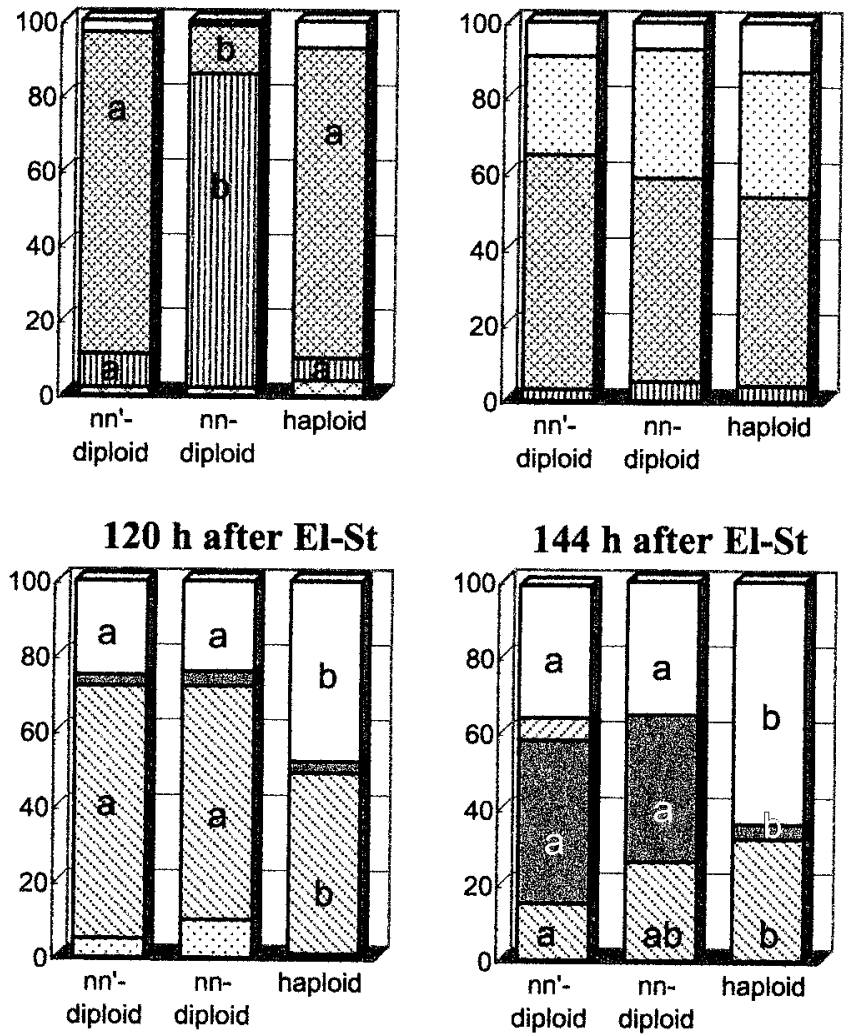

$144 \mathrm{~h}$ after El-St

$168 \mathrm{~h}$ after EI-St

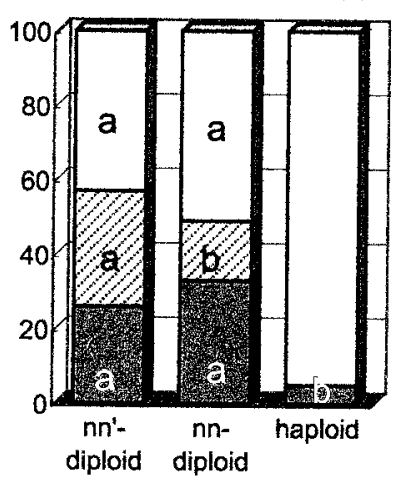

$192 \mathrm{~h}$ after El-St
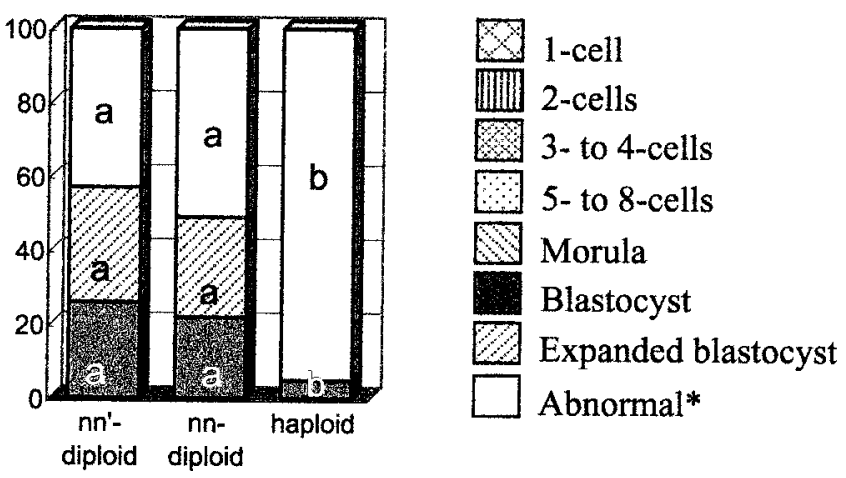

Fig. 2. Comparison of the developmental ability among parthenogenetic oocytes with genomic components of haploid, homogeneous diploid (nn-diploid) and heterogeneous diploid (nn'diploid)

*: Abnormal means parthenogenetic oocytes with features of degeneration and/or developmental delay. Figures on the top of columns at $24 \mathrm{~h}$ show numbers of oocytes evaluated. Values among different letters within each developmental stage are significantly different $(\mathrm{P}<0.05)$.

than $90 \%[5,7]$. Other studies have also reported that the genomic component was haploid in more than $90 \%$ of activated oocytes, and only a few percentages of stimulated oocytes were diploids [7,
13]. In the present study, $93 \%$ to $97 \%$ of electrostimulated oocytes were haploid (Table 1).

The first cleavage of parthenogenetic haploids was synchronized, and most haploids (97\%) began 
their first mitotic cleavage at around $16 \mathrm{~h}$ after El-St (Experiment 1). Since the most advanced nuclear stage of haploids 20 to $22 \mathrm{~h}$ after El-St was the anaphase to telophase, the completion of the first cleavage was estimated to occur at approximately $24 \mathrm{~h}$ or less after El-St. This observation is also supported by our previous report [7]. The results of Experiment 2 showed that the first cleavage of parthenogenetic haploids was efficiently prevented in the oocytes treated for $4 \mathrm{~h}$ with CB from $20 \mathrm{~h}$ after El-St.

Increasing the duration of CB treatment from 4 to $6 \mathrm{~h}$ led to improved efficiency of the duplication of the haploid genome (Table 3). Experimental haploid-genome duplication is usually induced just after activation via suppression of the extrusion of the second polar body [5,7]. In this case, all maturated oocytes are in the metaphase of the second meiosis. Ninety-five percent of activated oocytes reached the condensed-chromatin stage, and the process of the extrusion of the second polar body was completed within $2 \mathrm{~h}$ after the beginning of electro-activation $[2,3]$. On the other hand, it took about $2 \mathrm{~h}$ from the anaphase to telophase of the first cleavage (Experiment 1). Thus, in the first mitotic cleavage of the parthenogenetic haploid, the nuclear stage was not only exactly synchronized, but the duration of the cell division was slightly longer than the second meiosis. These differences may indicate that 4-h CB treatment resulted in greater efficiency of haploid-genome duplication during the second meiosis than during the first mitotic cleavage.

In Experiments 1 and 2, the efficiency of duplication of the haploid genome was estimated by the number of cells in activated oocytes. The mean frequency of estimated and confirmed diploids was $72 \%$ from 26 to $48 \mathrm{~h}$ after El-St (Table 4). Since the chromosomes could be counted only in oocytes in the metaphase, there was a high frequency of oocytes with undetermined ploidy during the first cleavage. The number of chromosomes could be counted in only 38 of 233 oocytes, and the frequency of diploids was $84 \%$, almost identical to that estimated $(82 \%)$ by the developmental stage 44 to $48 \mathrm{~h}$ after El-St (Table 4). This result suggests that the ploidy of each oocyte can be estimated from the developmental stage 44 to $48 \mathrm{~h}$ after El-St without fixation when haploid parthenogenetic oocytes are prevented from undergoing first haploid cleavage for duplication of their genomic component in our experimental condition. The observation of the oocytes at 2-h intervals from the end of CB treatment to $48 \mathrm{~h}$ after El-St showed that the duplicated diploid formed two haploid nuclei, and that the two haploid nuclei behaved like the female and male pronuclei in the fertilized egg [21].

The results in Experiment 4 reveal that all of the parthenogenetic oocytes with different nuclear components, haploid, nn'-diploid and nn-diploid, were able to develop to the blastocyst stage in vitro. The cleaving ability of haploids during the first three cleavages was high, and was nearly identical to that of nn'-diploids before $96 \mathrm{~h}$ after El-St. The frequency of the formation of the morula, however, was significantly lower in haploids $(48 \%)$ than in nn'- $(67 \%)$ or nn-diploids (62\%) $120 \mathrm{~h}$ after El-St (P $<0.05)$. In contrast, 62 embryos of 84 morulae in nn'-diploids and 47 embryos of 74 morulae in nndiploids formed the blastocoel at $144 \mathrm{~h}$, and only 4 embryos of 47 haploid morulae developed to the blastocyst stage. Thirty-one of 47 haploid morulae turned slightly dark, and some of them showed signs of decompaction at $144 \mathrm{~h}$, indicating that they were beginning to degenerate. Thus the ploidy of the parthenogenetic porcine oocytes severely affects the developmental ability to the blastocyst stage, especially the formation of the blastocoel in vitro. Although failure of porcine parthenogenetic haploids to develop to the blastocyst stage has also been reported, the development of diploids in these reports was also very low $[7,11]$. Because the developmental ability of diploids has become remarkably high due to improvements in culture system for porcine embryos $[6,13,20]$, we here investigated and elucidated the cause of the failure of the development in haploids.

Although an obvious developmental delay was observed 24 and $48 \mathrm{~h}$ after El-St in nn-diploids because of inhibition of the first cleavage, $\mathrm{nn}^{\prime}$ - and nn-diploids showed a quite similar distribution of developmental stages at each observation period later than $72 \mathrm{~h}$ after El-St. This fact indicates that the timing of compaction was dependent on the number of cleavages, or the duration from the onset of the development, namely the activation. A single blastomere produced by splitting the normal 2-cell embryo has been shown to form a blastocoel at the same time as the intact fertilized embryo irrespective of the number of cells in mice [22], sheep [23] and rats [24]. On the other hand, the 
recovery of the number of cells in nn-diploids was also suggested from the distribution of the developmental stages between $\mathrm{nn}^{\prime}$ - and nndiploids 72 and $96 \mathrm{~h}$ after El-St. The number of cells in the blastocysts recovered at $192 \mathrm{~h}$ after El-St in $\mathrm{nn}$ - and nn-diploids was not significantly different. The frequency of blastocysts at 168 and $192 \mathrm{~h}$ was slightly higher in nn'-diploids than in nn-diploids, although the difference was not significant $(\mathrm{P}>0.05)$.

In conclusion, this study has demonstrated that ploidy of activated oocytes, but not homology of alleles, affects the development of parthenogenesis to the blastocyst stage in the pig. Future experiments are needed to compare the developmental ability between heterogeneous and homogeneous diploids in the early stage of postimplantation after transfer to sows.

\section{Acknowledgments}

The authors are grateful to the staff of the Nishiharima and Hanshin Meat Inspection Offices of Hyogo Prefecture and the Meat Inspection Office of Kobe City for their provision of pig ovaries. This study was supported by a Grant-in-Aid from JSPS (JSPS-RFTF97L00905) and a Grant-in-Aid for Scientific Research (B-2, No. 09460129) from the Ministry of Education, Science, Sports, and Culture of Japan.

\section{References}

1. Kaufman MH. Mammalian parthenogenesis: background to experimental studies, terminology and pathways of development. In: Early Mammalian Development: Parthenogenetic Studies. Cambridge: Cambridge University Press; 1983: 119.

2. Kure-bayashi S, Miyake M, Kohno K, Miyano T, Kato $\mathbf{S}$. The meiotic resumption and cleaving ability of porcine oocytes maturated in-vitro and followed by electroactivation. J Mamm Ova Res 1994; 11: 164174.

3. Sun FZ, Hoyland J, Huang X, Mason W, Moor RM. A comparison of intracellular changes in porcine eggs after fertilization and electro-activation. Development 1992; 115: 947-956.

4. Funahashi H, Cantley TC, Stumpf TT, Terlouw SL, Day BN. In vitro development of in vitro-matured porcine oocytes following chemical activation or in vitro fertilization. Biol Reprod 1994; 50: 1072-1077.

5. Wang WH, Machaty Z, Abeydeera LR, Prather RS, Day BN. Parthenogenetic activation of pig oocytes with calcium ionophore and the block to sperm penetration after activation. Biol Reprod 1998; 58: 1357-1366.

6. Kure-bayashi S, Miyake M, Katayama M, Miyano T, Kato S. Improvement of developmental ability to the blastocyst stage by addition of hyaluronic acid to chemically defined medium in diploid porcine eggs matured in-vitro and subsequently electro-activated. J Mamm Ova Res 1995; 12: 119-125.

7. Kure-bayashi S, Miyake M, Katayama M, Miyano T, Kato S. Development of porcine blastocyst from in vitro-maturated and activated haploid and diploid oocytes. Theriogenology 1996; 46: 1027-1036.
8. Kure-bayashi S, Miyake M, Okada K, Kato S. Successful implantation of in vitro-matured electroactivated oocytes in the pig. Theriogenology 2000; 53: 1105-1119.

9. Mayes MA, Stogsdill PL, Prather RS. Parthenogenetic activation of pig oocytes by protein kinase inhibition. Biol Reprod 1995; 53: 270-275.

10. Nussbaum DJ, Prather RS. Differential effects of protein synthesis inhibitors on porcine oocyte activation. Mol Reprod Dev 1995; 41: 70-75.

11. Kim NH, Uhm SJ, Ju JY, Lee HT, Chung KS. Blastocoele formation and cell allocation to the inner cell mass and trophectoderm in haploid and diploid pig parthenotes developing in vitro. Zygote 1997; 5: 365-370.

12. Tarkowski AK, Witkowska A, Nowicka J. Experimental parthenogenesis in the mouse. Nature 1970; 226: 162-165.

13. Miyake M, Kure-bayashi S, Miyano T, Harayama H, Kato S. Electric activation of porcine oocytes and their development in vitro and in vivo. In: Miyamoto $\mathrm{H}$, Manabe N (eds.), Reproductive Biology Update-Novel Tools for Assessment of Environmental Toxicity-. Nakanishi Pub. Co., Kyoto, Japan; 1998: 117-127.

14. Surani MA, Barton SC, Norris ML. Development of reconstituted mouse eggs suggests imprinting of the genome during gametogenesis. Nature 1984; 308: 548-550.

15. Barton SC, Adams CA, Norris ML, Surani MA. Development of gynogenetic and parthenogenetic inner cell mass and trophectoderm tissues in reconstituted blastocysts in the mouse. J Embryol Exp Morphol 1985; 90: 267-285. 
16. Surani MA, Barton SC, Norris ML. Influence of parental chromosomes on spatial specificity in androgenetic-parthenogenetic chimaeras in the mouse. Nature 1987; 326: 395-397.

17. Zimmermann U, Viemken J. Electric field-induced cell-to-cell fusion. J Memb Biol 1982; 67: 165-182.

18. Whitten WK, Biggers JD. Complete development in vitro of the pre-implantation stages of the mouse in a simple chemically defined medium. Reprod Fertil 1968; 17: 399-401.

19. Miyano T, Hiro-oka RE, Kano K, Miyake M, Kusunoki H, Kato S. Effects of hyaluronic acid on the development of 1- and 2-cell porcine embryos to the blastocyst stage in vitro. Theriogenology 1994; 41: 1299-1305.

20. Nguyen VT, Harayama $H$, Nagai T, Miyake $M$.
Stage-specific effects of the osmolarity of a culture medium on the development of parthenogenetic diploids in the pig. Theriogenology 2002 (In press).

21. Longo FJ. Fertilization: a comparative ultrastructural review. Biol Reprod 1973; 9: 149-215.

22. Smith R, McLaren A. Factors affecting the time of formation of the mouse blastocoel. J Embryol Exp Morphol 1977; 41: 79-92.

23. Willadsen SM. A method for culture of micromanipulated sheep embryos and its use to produce monozygotic twins. Nature 1979; 277: 298300.

24. Matsumoto K, Miyake M, Utsumi K, Iritani A. Production of identical twins by separating two-cell rat embryos. Gamete Res 1989; 22: 257-263. 